\title{
The British 1967 Abortion Act-still fit for purpose?
}

Oct 27, 2017 marks the 50th anniversary of the British Abortion Act, written "to amend and clarify the law relating to termination of pregnancy by registered medical practitioners". ${ }^{1}$ Amended in 1990 to include selective reduction of a multiple pregnancy, the Abortion Act governs abortion in England, Scotland, and Wales (Britain), the first law in western Europe to formally legalise abortion for several indications.

Abortion is common. Worldwide, an estimated $25 \%$ of all pregnancies end in abortion ${ }^{2}$ and one in three women in Britain will have an abortion by age 45 years. ${ }^{3}$ In 2016, there were more than 200000 safe abortions in Britain.,4 Yet abortion remains controversial-its availability across the world depends less on medical or public health need and more on religious, moral, and political beliefs. Restricting access to abortion does not deter women from seeking one but drives them to unsafe, clandestine procedures from which they may die. In 2011, rates of unsafe abortion were three times higher in countries with more restrictive abortion laws compared with countries with less restrictive laws. ${ }^{5}$ Abortion laws are generally more restrictive in lowincome and middle-income countries (LMICS); only $20 \%$ of LMICs allow abortion for socioeconomic reasons and $16 \%$ on request. ${ }^{5}$ Restrictive policies do not reduce abortion rates. In 2010-14, rates were estimated at 34 abortions (90\% uncertainty interval 29-46) per 1000 women in countries where abortion is legal on request and 37 (34-51) per 1000 women in countries with no legal grounds for abortion. ${ }^{2}$

Liberalising abortion laws saves women's lives. In Romania, the relaxation of abortion legislation in 1989 led to maternal mortality falling by more than $50 \%$ in less than 1 year. ${ }^{6} \mathrm{An}$ analysis by the Guttmacher Institute of countries that have lifted some restrictions to access over the past two decades showed a decline in abortion-related mortality and morbidity. ${ }^{7}$ There is no doubt that in those countries with restrictive laws, 50 years of legislation similar to the 1967 Act would have saved millions of lives.

Nevertheless, the 1967 Abortion Act in Britain is outdated, placing unjustified and time consuming barriers in the way of women seeking an abortion. Two doctors must give written approval and the procedure must be undertaken in an "approved" place and notified to the Chief Medical Officer. Much has changed in Britain since 1967, when all abortions were undertaken surgically. Abortion today is a simpler and safer procedure: in 2016,62\% of all abortions in England and Wales ${ }^{3}$ and $83 \%$ in Scotland ${ }^{4}$ were medical abortions (mifepristone and misoprostol administered in a health-care setting). The National Health Service (NHS) has also changed. Nurses now do colposcopies, cystoscopies, hysteroscopies, and manage women who have miscarriages, including surgical evacuation of the uterus. Despite their competence, nurses are not allowed to carry out the same procedure for a woman seeking an abortion. Homecare is available for many NHS procedures, including intravenous chemotherapy and renal dialysis, yet despite good evidence that women can manage their own medical abortion at home ${ }^{8}$ this too remains illegal under the 1967 Act.

Many people in the UK mistakenly believe that it is easy for women to get an abortion. Aitken and colleagues ${ }^{9}$ documented the experiences of 519 women who over 4 months contacted one online non-profit initiative that provides early medical abortion. The reasons cited by these women were the sometimes insurmountable barriers they met trying to access NHS abortions, including long waiting times, distance to clinic, constraints due to work or childcare commitments, hesitation due to previous negative experiences of abortion care, and perceived or experienced stigma. Many women said they would like the option of self-administering abortion pills in the privacy and comfort of their own home. ${ }^{9}$ 
If a woman in the UK today ends her pregnancy without the permission of two doctors she can be sentenced to life imprisonment. The availability of abortifacients online makes this scenario more likely than in the past. No other medical procedure in Britain is subject to the same criminal sanctions as abortion. There is growing support for decriminalisation of abortion and for the procedure to instead be subject to appropriate regulatory and professional standards, in line with other medical procedures. ${ }^{10}$ In the past 2 years, the Royal College of Obstetricians and Gynaecologists, the British Medical Association, and the Royal College of Midwives have backed calls for the decriminalisation of abortion-supporting the removal of criminal sanctions associated with abortion in the UK. ${ }^{10}$ There is a political reluctance to challenge the 1967 Act for fear, perhaps justifiably, that it may become more restrictive, particularly with respect to the gestational age limit which is repeatedly raised in Parliamentary discussions on abortion. ${ }^{11}$

The 1967 Abortion Act does not extend to Northern Ireland where abortion care is only provided under very limited circumstances when there is a significant and long-term threat to a woman's physical or mental health. ${ }^{12}$ As a result, more than 700 women each year travel from Northern Ireland to have an abortion in other parts of the UK at a huge personal cost. ${ }^{3}$ Those who are unable to afford to travel to the UK, are forced to use abortifacients bought online, illegally-and risk up to life imprisonment. In 2016, two Northern Irish women were given a jail sentence for buying abortifacients online and then self-administering them. ${ }^{13}$ After a decadeslong struggle, in June, 2017, the UK Government changed its policy to give Northern Irish women access to free terminations on the NHS in England. ${ }^{14}$ Although this is a welcome step in the right direction, women in Northern Ireland should have the same access to abortion care as women in England, Scotland, and Wales. There will always be women who will be unable to travel. For example, women who have families, those who cannot afford to take time off work, and women who do not meet the UK Government's criteria for free travel and accommodation. ${ }^{15}$

Abortion is disappearing from the workload of many gynaecologists in England and Wales which has led to complacency about its provision and about the law. In Scotland almost all abortions take place in NHS premises, whereas in England and Wales 70\% of abortions are now undertaken in the independent sector although funded by the NHS.,4 Most importantly, because abortions are now rarely undertaken in hospitals in England an imminent crisis in service provision is likely because training in abortion care is simply no longer available in the NHS for most junior doctors.

We must never forget that the fight to reform the abortion law took over 30 years and that before 1967, abortion accounted for $14 \%$ of all maternal deaths in Britain. ${ }^{16}$ The average age of first sex in Britain is 16 years, the average age of first birth 30 years, and most women wish for only two children (some $17 \%$ want none). ${ }^{17}$ This means that most women spend their fertile lives trying to avoid unintended pregnancy. No contraceptive method is $100 \%$ perfect. The reality is that women will always need to access abortion and we need to re-learn how to provide better care. We must ensure that the next generation of girls and women in the UK and across the globe have access to timely abortion care and that this service remains a crucial part of women's health care in 50 years from now.

*Lesley Regan, Anna Glasier

Royal College of Obstetricians and Gynaecologists, London NW1 4RG, UK (LR); Section of Obstetrics and Gynaecology, [I had to omit St mary's Capus because of space] Faculty of Medicine, Imperial College London, London, UK (LR); College of Medicine and Veterinary Medicine, University of Edinburgh, Edinburgh, UK (AG); and Faculty of Public Health and Policy, London School of Hygiene and Tropical Medicine, London, UK (AG)

policy@rcog.org.uk 
LR is President of the Royal College of Obstetricians and Gynaecologists, a member of the British Society of Abortion Care Providers, and the Programme Director for Leading Safe Choices. AG is on the Board of Trustees for the British Pregnancy Advisory Service and is a Programme Advisor for Leading Safe Choices. We declare no other competing interests.

1 UK Government. The National Archives. Abortion Act 1967. London: HM Stationery Office, 1967. https://www.legislation.gov.uk/ukpga/1967/87/contents (accessed Oct 15, 2017).

2 Sedgh G, Bearak J, Singh S, et al. Abortion incidence between 1990 and 2014: global, regional, and subregional levels and trends. Lancet 2016; 388: 258-67.

3 UK Government. Abortion statistics, England and Wales: 2016 summary information from the abortion notification forms returned to the Chief Medical Officers of England and Wales. https://www.gov.uk/government/statistics/report-on-abortion-statistics-inengland-and-wales-for-2016 (accessed Oct 15, 2017).

4 Information Services Division. Termination of pregnancy statistics year ending December 2016. 2017. http://www.isdscotland.org/Health-Topics/Sexual-Health/Publications/201705-30/2017-05-30-Terminations-2016-Summary.pdf (accessed Oct 15, 2017).

5 United Nations, Department of Economic and Social Affairs, Population Division. Abortion policies and reproductive health around the world. 2014.

http://www.un.org/en/development/desa/population/publications/pdf/policy/AbortionP oliciesReproductiveHealth.pdf (accessed Oct 15, 2017).

6 Stephenson P, Wagner M, Badea M, Serbanescu F. Commentary: the public health consequences of restricted induced abortion-lessons from Romania. Am J Public Health 1992; 82: 1328-31.

7 Guttmacher Institute. Making abortion services accessible in the wake of legal reforms: a framework and six case studies. New York: Guttmacher Institute, 2012.

8 Ngo TD, Park MH, Shakura H, Free C. Comparative effectiveness, safety and acceptability of medical abortion at home and in a clinic: a systematic review. Bull World Health Organ 2011; 89: 360-70.

9 Aiken ARA, Guthrie KA, Schellekens M, Trussell J, Gomperts R. Barriers to accessing abortion services and perspectives on using mifepristone and misoprostol at home in Great Britain. Contraception 2017; published online Sept 20.

DOI:10.1016/j.contraception.2017.09.003.

10 Campbell D. Abortion should not be a crime, say Britain's childbirth doctors. The Guardian, Sept 22, 2017.

11 House of Commons Science and Technology Committee (2007). Scientific Developments Relating to the Abortion Act 1967 Twelfth Report of Session 2006-07. London: The Stationery Office, 2007.

12 Department of Health, Social Services and Public Safety. Guidance for health and social care professionals on termination of pregnancy in Northern Ireland. Belfast: Department of Health, Social Services and Public Safety, 2016.

13 British Medical Association. Decriminalisation of abortion: a discussion paper from the BMA. London: British Medical Association, 2017.

14 Stone J, Merrick R. Government U-turns on NHS abortions for Northern Ireland women. The Independent, June 29, 2017.

15 Elgot J. Northern Irish women offered free abortion services in England. The Guardian, Oct 24, 2017. 
16 Walker AL, Wrigley AJ, Organe GSW, Chamberlain RN, Martin JW. Ministry of Health reports on public health and medical subjects no. 103. Report on confidential enquiries into maternal deaths in England and Wales 1955-57. London: HM Stationery Office, 1960. 17 Office for National Statistics. Statistical Bulletin: childbearing for women born in different years England and Wales: 2015. London: Office for National Statistics, 2016.[I had to remove url because of space] 